Nuntius Antiquus, Belo Horizonte, v. 11, n. 2, p. 71-82, 2015

\title{
Cólera e outras emoções em $A$ árvore da vida de T. Malick
}

\section{Anger and other emotions in T. Malicks' Tree of life ${ }^{1}$}

\section{Christian Werner}

Faculdade de Filosofia, Letras e Ciências Humanas da USP

crtwerner@hotmail.com

Resumo: Esse texto discute o filme Tree of life (A árvore da vida) de T. Malick (2011), abordando sua composição fragmentária e as visões de mundo de suas personagens principais por meio da teoria das emoções de Aristóteles desenvolvida na Retórica. Mostra-se que sua definição da cólera é particularmente relevante para o filme em questão.

Palavras-chave: $A$ árvore da vida; Terrence Malick; Aristóteles; Retórica; emoções.

Abstract: This text discusses Malick's Tree of life (2011), approaching its fragmentary composition and the world views of its main characters by means of Aristotle's theory on emotions developed in his Rhetoric. It is argued that its definition of anger is particularly relevant for the film in question.

Keywords: Tree of life; Terrence Malick; Aristotle; Rhetoric; emotions.

1 Texto apresentado no evento "I Seminário Docere, Delectare et Mouere: Emoções
Aristotélicas no Cinema" (Centro de Convenções do Complexo Santuário do Caraça, na
região da cidade de Santa Bárbara, Minas Gerais, de 10 a 13 de março de 2015 , <www.letras.
ufmg.br/doceredelectareetmovere>) organizado por Maria Cecília de Miranda Nogueira
Coelho (Departamento de Filosofia da FAFICH-UFMG), como coordenadora geral, e por
Helcira Maria Rodrigues de Lima, Sérgio Alcides Pereira do Amaral e Teodoro Rennó
Assunção (todos três da FALE/UFMG), e promovido pelo Grupo de Pesquisa "Retórica
e Argumentação", do CNPq e UFMG (FAFICH-FALE), pelo "Núcleo de Estudos Antigos
e Medievais" (NEAM) do CNPq e UFMG (FALE-FAFICH), com apoio da CAPES, da
FAPEMIG, do PPG-FIL da FAFICH/UFMG, do PÓS-LIN e do PÓS-LIT da FALE/UFMG. 
Recebido em 24 de julho de 2015 Aprovado em 14 de setembro de 2015

Um dos fios condutores do fragmentário filme Tree of life - em português, $A$ árvore da vida $-^{2}$ são as emoções de suas personagens principais, intrínsecas às formas diferentes como reagem aos eventos que os atingem. Meu propósito neste texto é investigar as formas da cólera de duas de suas personagens principais, o pai (o Sr. O'Brien) e o filho mais velho quando pré-adolescente (Jack). Para isso, vou fazer o filme dialogar com a teoria das emoções desenvolvida por Aristóteles na Retórica, o que não significa que eu esteja propondo que o fundamento cultural que permitiu a teorização aristotélica esteja mais próximo do núcleo do filme que, por exemplo, o imaginário judeo-cristão. A composição do filme, porém, pela qual inicio minha discussão, e o viés essencialmente dialógico do cinema de Terrence Malick, ${ }^{3}$ um diretor com sólida formação filosófica (RYBIN, 2012, passim; TUCKER \& KENDALL 2011), convidam o crítico a submetê-lo a diferentes abordagens. Assim, na segunda parte do meu texto, farei o filme interagir com a discussão aristotélica da "retórica das paixões".

\section{A composição de Arvore da Vida}

Funcionando como um contraponto ou moldura para sua composição fragmentária, $A$ árvore da vida abre com três textos que poderíamos chamar de programáticos, os quais conferem uma certa ordem ou indicam uma certa forma ao que segue, muito embora essa ordem ou forma só tenda a ficar mais clara, e seu sentido, mais palpável, ao se ver o filme pela segunda vez. O primeiro texto é uma citação de Jó. Quase

\footnotetext{
${ }^{2}$ Dados técnicos do filme de 2011: produção: Cottonwood Pictures, Plan B Entertainment, River Road Entertainment; diretor: Terrence Malick; roteiro: idem; diretor de fotografia: Emmanuel Lubezki; editores: Hank Corwin, Jay Rabinowitz, Daniel Rezende, Billy Weber, Mark Yoshikawa; proporção de tela: 1.85:1; elenco: Brad Pitt (Sr. O’Brien), Sean Penn (Jack), Jessica Chastain (Sra. O'Brien), Hunter McCracken (jovem Jack), Laramie Eppler (R. L.), Tye Sheridan (Steve), Fiona Shaw (avó).

${ }^{3}$ Esse se verifica da forma mais explícita e, eventualmente, bem-acabada em The thin red line (Além da linha vermelha, T. Malick 1998), no qual um dos discursos - o de Tall (Nick Nolte) - poderia ser categorizado, de forma aproximada, de iliádico ou homérico, o que se sustenta por uma menção explícita a Homero.
} 
no início do primeiro discurso de Iahweh, ele se dirige a Jó do meio de uma tempestade e lhe fala sobre a criação: "Where were you when I laid the foundations of the Earth, when the morning stars sang together, and all the sons of God shouted for joy?"' Enquanto se vê esse trecho na tela, em um fundo negro, ouve-se o som do mar e de gaivotas, um conjunto que, mais tarde, formará um par com uma imagem igualmente programática, aquela que se oporá ao deserto no qual vive a personagem central do filme, Jack O'Brien, cujo nome remete à figura bíblica ("Job", em inglês), o sofredor por excelência.

O segundo texto é dito por Jack adulto, representado por Sean Penn, sem que ele apareça em tela. Sua voz, porém, familiar a uma boa parte do público do filme, sugere que se ouve uma fala de uma personagem central do filme. O discurso em "off", uma das marcas registradas de Malick, é acompanhado pelo som das gaivotas e do mar. Enquanto isso, vê-se uma chama, signo que retornará ao longo do filme e que, como já notou pelo menos um crítico, serve de divisor entre algumas partes dele (LEITHART, 2013, p. 25-26). Diz Jack: "Brother... Mother... It was they who led me to your door".

Jack nitidamente dirige-se a um terceiro ausente ("your") que o filme irá sugerir tratar-se de Deus ou de uma ideia ou visão de mundo que poderíamos chamar desse modo. A frase também aponta para a imagem central da busca ou trajetória de Jack, a porta. Essa trajetória ou busca estará presente de diversas formas no filme: em boa medida, ela é o próprio filme, mas também se concentra nas imagens, vividas ou imaginadas, que resultam das experiências de Jack adulto no dia do aniversário da morte de seu irmão. Não sabemos como ele morreu, somente que isso aconteceu em algum momento no final de sua adolescência. O que vemos é a notícia da morte dada aos pais e seu sofrimento posterior, bem como seu quarto vazio no qual se destaca o violão que tocava com prazer e bem.

Entre essa frase e a citação de Jó lida pelo espectador anteriormente estabelece-se algo intermediário entre um diálogo e uma complementaridade: “- Onde tu (Jó a Iahweh) estavas? - Eles (irmão e mãe) me levaram a

\footnotetext{
4 "Onde estavas quando estabeleci as fundações da Terra, quando as estrelas da manhã cantaram em conjunto, e todos os filhos de Deus gritaram de alegria?". As traduções de citações do filme são minhas. O filme informa que a passagem está em Jó 38: 4, 7. 5 "Irmão... Mãe... Foram eles que me levaram a tua porta".
} 
ti (Deus?)." Isso nos remete a uma outra marca registrada de Malick, a quase ausência de diálogo entre as personagens que compõe uma cena. ${ }^{6}$ Seus filmes, porém, são dialógicos de outras formas. Em $A$ árvore da vida, isso se dá, por exemplo, por meio de discursos em "off" que se assemelham a preces: sua resposta nunca é ouvida, mas se manifesta por meio de imagens da composição fílmica. Nesse sentido, embora a citação que abra o filme, dada para nossa leitura enquanto ouvimos sons da natureza, reproduza a palavra de Deus em um diálogo que se dá em um livro bíblico composto, basicamente, por diálogos, o que se ouve na sequência é uma personagem se comunicando com um Deus que é, ao mesmo tempo, imanente à natureza, representada pelo som do mar e das gaivotas, mas também ligado, de alguma forma, à imagem da chama, que é, por sua vez, ao mesmo tempo uma imagem tradicional de representação do divino (LEITHART, 2013, p. 25-31) mas também um signo opaco, aberto, arbitrário, intrínseco à construção particular que é o filme.

A chama lentamente desaparece, e começa-se a ouvir uma obra sacra e fúnebre, "Funeral canticle", do compositor inglês, falecido em 2013, John Tavener, e ela acompanha uma longa fala em "off” de uma figura feminina que, saberemos mais tarde, é a mãe de Jack, identificada no filme apenas como a Sra. O'Brien: é o terceiro discurso programático do filme. Quando essa fala termina ("the nuns taught us that no one who loves the way of grace ever comes to a bad end"; grifo meu) ${ }^{7}$ e aparece a imagem de uma caudalosa cachoeira, transcorreram menos de quatro minutos do filme, mas, por meio da densa composição polifônica criada pelo texto, pelas imagens e pelos sons, o núcleo temático do filme já nos foi apresentado.

A narração da Sra. O’Brien inicia com uma imagem dela em uma fazenda quando criança, provavelmente com seu pai. A voz que ouvimos, porém, é de Jessica Chastain, a atriz que a representa quando adulta e que, em 2008, ano das filmagens, era virtualmente desconhecida; sua voz, portanto, deve ter sido identificada por uma pequena parcela do público originário do filme. Enquanto ainda fala da graça, há um corte abrupto para um quadro que a mostra adulta, brincando com os filhos. Isso reforça a impressão, mais forte quando vemos o filme pela segunda

\footnotetext{
${ }^{6}$ Em comparação com seu filme seguinte, To the wonder (T. Malick, 2012), fala-se muito em The tree of life.

7 “As freiras nos ensinaram que ninguém que ama o caminho da graça um dia terminará mal".
} 
vez, que sua fala faz parte daquilo que R. L., as iniciais do filho do meio, chamará de "a story from before we can remember", ${ }^{8}$ sugerindo-nos que a voz e as imagens que vemos são mediadas pela memória dos filhos, mais precisamente, pela memória de Jack adulto. Não é a Sra. O'Brien que se comunica diretamente com o público do filme, ou, pelo menos, não é somente isso que ocorre. Na escolha desta fala, cujo início também abria o trailer do filme, e na forma como ela nos é apresentada, também está presente a subjetividade de Jack adulto, o que é sugerido, inicialmente, pela ligação entre o segundo e o terceiro textos programáticos do filme. Assim, o filme que veremos é em certa medida, uma construção feita por Jack; por essa razão, a primeira fala do filme é dele. Não é nítida a fronteira entre Jack e o diretor do filme, que escolhe o primeiro texto programático que vemos, a citação de Jó.

$\mathrm{O}$ uso de flashbacks neste filme, portanto, se dá de uma forma complexa. Nas palavras de um crítico, o que vemos é uma "narrativa de rememoração" e não uma representação objetiva do passado; as imagens da infância são aquilo que Jack "procura" (RYBIN, 2012, p. 177). Um elemento que reforça essa interpretação é que esse se tratava do filme mais autobiográfico de Malick até então. ${ }^{9}$ Não só ele cresceu no Texas, o estado em que se passa o filme, com dois irmãos, mas um deles, aluno de Andrés Segovia - a habilidade no violão distingue o irmão de Jack que morre no fim da adolescência -, frustrado com seu desempenho, primeiro mutilou suas mãos e, na sequência, se matou (TUCKER \& KENDALL, 2011, p. 4-5).

Todavia, assim como praticamente nada sabemos sobre Terrence Malick, avesso a aparições públicas e entrevistas, poucos dados objetivos nos são apresentados pelo filme acerca de seu alter ego Jack. Que se trata de um alter ego, isto é sugerido não apenas pelas coincidências biográficas, mas porque a nossa experiência fílmica é resultado da atividade do diretor e do próprio Jack, tema ao qual voltaremos abaixo. Não somos convidados a buscar explicações sobre a vida presente de Jack e, da mesma forma, nada ganhamos em pensar o filme a partir de fragmentos da vida de seu autor extra-fílmico; somos deslocados para o centro do filme, sua geração, o complexo processo de lembrança que é, ao mesmo tempo, uma busca de sentido para a própria vida, o mundo e Deus.

\footnotetext{
8 "Uma estória de antes do que conseguimos lembrar".

${ }^{9}$ To the wonder, que o seguiu em poucos anos, também foi bastante autobiográfico.
} 


\section{As emoções em $\boldsymbol{A}$ árvore da vida: um viés aristotélico}

Para introduzir a discussão das emoções em Aristóteles, volto à frase da Sra. O'Brien. Enquanto nós vemos imagens dela, criança, olhando para fora de uma janela e, na sequência, segurando um cabrito e olhando primeiro para o céu, depois para vacas e, finalmente, para um campo de girassóis, ${ }^{10}$ ela anuncia o tema de seu discurso, os caminhos da natureza e da graça, um dos quais todo homem precisa escolher: "The nuns taught us there were two ways through life - the way of nature and the way of grace. You have to choose which one you'll follow". ${ }^{11}$ Antes de começar a falar da graça, desfilam imagens da natureza, talvez sugerindo uma interpretação teológica possível, a de que a graça também está - ou, pelo menos, de que também possa estar - na natureza. ${ }^{12}$ No momento em que fala da graça, surge a imagem de seu pai, com o qual a vemos em momentos de intensa proximidade física: "Grace doesn't try to please itself. Accepts being slighted, forgotten, disliked. Accepts insults and injuries". ${ }^{13}$ Novo corte, mais abrupto, para a Sra. O'Brien adulta, em uma cena de harmonia entre ela e seus três filhos que reflete a idealização de sua infância.

A graça é primeiro definida negativamente, em descompasso com as imagens que vemos. Compare-se essa definição com o modo como Aristóteles define a cólera: "A desire, accompanied by pain, for a perceived revenge, on account of a perceived slight on the part of people who are not fit to slight one or one's own" (Ret. 1378a 31-3).${ }^{14}$ Trata-se da busca de

\footnotetext{
${ }^{10}$ Esse campo volta no fim do filme de uma forma que reforça a ideia de que o filme é uma construção conjunta de Jack e de T. Malick.

11 "As freiras nos ensinaram que há dois caminhos pela vida - o caminho da natureza e o da graça. Você precisa escolher qual irá seguir".

${ }^{12}$ Concordo com Rybin (2012, p. 172) que "Malick himself does not quite call upon the viewer to choose either grace or nature"; ele está interessado em mostrar como às vezes as duas formas, entrelaçadas, constituem um conflito permanente no interior do indivíduo. 13 "A graça não tenta comprazer-se a si mesma. Aceita ser menosprezada, esquecida, detestada. Aceita insultos e ferimentos".

${ }^{14}$ A tradução é de Konstan (2003, p. 100), que escolhi para reforçar as semelhanças com o trecho em inglês do filme; Ísis da Fonseca (Aristóteles, 2000, p. 7) traduz o trecho assim: "Seja, então, a cólera o desejo, acompanhado de tristeza, de vingar-se ostensivamente de um manifesto desprezo por algo que diz respeito a determinada pessoa ou a algum dos seus, quando esse desprezo não é merecido".
} 
um prazer, aquele da vingança, a única forma de acabar com a dor advinda do fato de ser objeto de menosprezo, em grego, oligoreîn, verbo que pode ser traduzido por "tratar como inferior, desrespeitar, desconsiderar, menosprezar". Na sequência, Aristóteles especifica quais são as espécies de desconsideração: desprezo, malevolência e ofensa arrogante. ${ }^{15}$

A definição aristotélica da cólera não está longe da definição negativa da graça, que, por sua vez, é contrária àquela de natureza, no filme corporificada pelo Sr. O’Brien, cujas atitudes mais negativas podem ser comparadas à forma de vingança exigida pela definição aristotélica.

Para Aristóteles, o contrário da cólera, para usar o termo preferido pela maioria dos tradutores e comentadores, é a calma. Na interpretação de David Konstan, porém, a praótes é antes "satisfação", uma noção que abarca o "comportamento humilde que aumenta a autoestima do outro e, por essa razão, o torna gentil" bem como a "compensação por um ataque ou insulto" (KONSTAN, 2006, p. 89). ${ }^{16}$ Para representar a opção pela graça, as imagens usadas por Malick - a mãe brincando quase ao modo de uma dança com seus filhos e um cão - podem ser aproximadas da seguinte passagem de Aristóteles: "Quando se acham em estado de ânimo contrário ao da cólera, é evidente que as pessoas são calmas, por exemplo, no jogo, no riso, na festa, num dia feliz, num momento de sucesso, na realização dos desejos e, em geral, na ausência da dor, no prazer inofensivo e na esperança justa" (Ret. 1380b 2-5). ${ }^{17}$

O Sr. O’Brien aparece pela primeira vez no filme no exato momento em que sua esposa começa a falar da "natureza". Isso ocorre durante um jantar, ocasião em que, por diversas vezes ao longo do filme, ele mostrará até que ponto corporifica a natureza. Na sequência imediata da cena em questão, porém, ele aparece brincando no jardim com o resto da família. Essa sequência de imagens sugere que, assim como no caso de Jack, o pai, embora aja do modo como as freiras definem natureza, também tem seus momentos de graça. Totalmente do lado da graça

${ }^{15}$ Traduzo as opções de Konstan (2003, p. 108-9): “contempt”, "spite” e "arrogant abuse”. ${ }^{16}$ Konstan (2006, p. 77) a define assim: "The elation or positive disposition consequent upon a compliment or other gesture that results in an enhanced opinion of a person's worth" ou "a desire, accompanied by pleasure, to treat someone kindly, on account of a perceived gesture of respect" (p. 85); Konstan concede, porém, que opta por termos que talvez extrapolem aqueles de Aristóteles (p. 89).

${ }^{17}$ Ret. abrevia a Retórica de Aristóteles: esta e todas as traduções da Retórica abaixo são de I. B. da Fonseca e estão em Aristóteles, 2000. 
aparecerá, além da mãe, R. L., o irmão que morre, ou seja, as duas figuras às quais Jack se dirige na abertura do filme.

A forma da "natureza” pela qual vive o Sr. O’Brien, entretanto, diz respeito tanto a momentos de cólera no sentido aristotélico como a um ressentimento generalizado. ${ }^{18}$ Ele separa os homens entre os que obtiveram e os que não obtiveram sucesso, e é do segundo grupo que faz parte, muito embora, diante da família, produza um discurso que sugere que pertence ou deveria pertencer ao primeiro grupo. Músico e inventor frustrado, ele usa a família como válvula de escape. O mundo, representado pelo tribunal com sua poderosa abóbada, ${ }^{19}$ nega-lhe suas patentes, ou seja, opõe-se à realização de seus desejos. ${ }^{20}$ Só lhe resta aparecer como superior diante da família, mesmo que de forma ridícula, por exemplo, quando informa que leu em uma revista a forma correta de sentar ou descreve, orgulhoso, o banheiro de aço do avião da PanAm após voltar de uma longa viagem.

Sua explosão de cólera mais violenta se dá quando R. L. lhe pede, durante um jantar, que fique quieto. Do seu ponto de vista, foi humilhado por quem não tem esse direito. Na realidade, não há nada que os filhos pudessem fazer neste dia terrível que pudesse ser sentido por ele como uma forma de consideração, já que foi (mais uma vez) ${ }^{21}$ derrotado no tribunal. Como o doente que se irrita com quem despreza sua doença, ${ }^{22} \mathrm{o}$

\footnotetext{
${ }^{18}$ Esse ressentimento não deve ser dissociado dos sentimentos negativos de Jack (ele mesmo se define como "bad" como o pai), que, por vez, se aproximam também do ódio aristotélico: "são causas do ódio a cólera, o ultraje, a calúnia. A cólera, pois, provém daquilo que nos toca pessoalmente, enquanto o ódio surge mesmo sem nenhuma ligação pessoal; de fato, se supomos que uma pessoa tem tal ou tal caráter, nós a odiamos" (Ret. 1382a 1-5).

${ }^{19}$ A arquitetura monumental liga o Sr. O'Brien a Jack adulto: no caso daquele, o tribunal e a fábrica onde trabalha; no caso deste, o prédio no qual trabalha, no centro de Austin, e seu possível trabalho de arquiteto. Vale mencionar que neste filme estão as primeiras imagens de uma metrópole moderna na filmografia do autor.

${ }^{20}$ Sobre a cólera, diz Aristóteles: "Encolerizam-se quando experimentam um desgosto, pois que o desgostoso sente desejo de algo; se, então, alguém se opõe a qualquer desejo, diretamente, como, por exemplo, quando obsta a que beba aquele que tem sede, ou indiretamente, parece que o efeito é o mesmo em ambos os casos..." (Ret. 1379a 12-15). ${ }^{21} \mathrm{Cf}$. a observação que lhe faz o advogado após o veredito: “next time..." ("na próxima vez"). 22 "Eis por que os doentes, os indigentes [os combatentes], os apaixonados, os sedentos, geralmente desejando algo e não conseguindo, encolerizam-se e facilmente se exaltam
} 
pai, incapaz de se vingar contra a instituição que está muito acima dele, vinga-se nos filhos, ele que, na relação com eles, tenta ensiná-los a ser uma versão melhorada de si mesmo, algo que, mais para o fim do filme, dirá que foi estúpido.

De forma homóloga, Jack também canaliza seus sentimentos para ações de uma violência gratuita, tentando mitigar um mal-estar que podemos aproximar da cólera tal como definida por Aristóteles. Vemos uma manifestação dessa emoção na cena em que presencia um instante de intimidade prazerosa entre o Sr. O'Brien, tocando piano na sala, e R. L., que, na varanda, o acompanha com o violão: ${ }^{23}$ ele fica de fora dessa ligação que se diferencia daquela que tem com o pai. Todavia, quando mais tarde machuca o irmão com uma arma de pressão, é menos uma vingança pessoal e mais uma vingança difusa contra algo que o oprime, imitando o pai. Esse tipo de vingança nunca parece causar algum prazer, já que não consegue eliminar a dor de algo sentido como um desrespeito que não é, em última instância, pessoal, uma dimensão da cólera não desenvolvida por Aristóteles. A chave para se sair desse círculo vicioso precisa ser buscada alhures, não sob a forma de uma vingança.

Quando o filme começa a ir para seu final, pouco antes de o Sr. O'Brien receber a notícia de que perdeu seu emprego, o que obriga a família a mudar de cidade, ouvimos mais uma vez a voz em "off" do jovem Jack: "I didn't know how to name you then. But I see it was you. Always you were calling me". ${ }^{24}$ Enquanto se escuta o final dessa frase, vê-se uma imagem do Rio Colorado, que passa pela pequena cidade de Smithville, no Texas, onde ocorreram as filmagens e que no filme é identificada, duas vezes como Waco, a cidade onde Malick passou parte de sua infância e que fica às margens do Rio Brazos, chamado de Rio de los Brazos de Dios pelos exploradores espanhóis. Nas sequências imediatamente anteriores, havíamos acompanhado Jack ferindo o irmão com uma arma de pressão, sem nenhuma razão aparente. Ele já havia feito algo semelhante, mas sem maiores consequências, com um abajur,

sobretudo com aqueles que pouca consideração mostram para com seu estado presente; por exemplo, o doente irrita-se com aqueles que desprezam sua doença" (Ret. 1379a 17-21). ${ }^{23}$ A porta da varanda, que, em outra cena, separa Jack e o pai, aqui une o outro filho ao pai. Já se mencionou acima que a imagem da porta é central no filme.

24 "Naquela época não sabia como nomear-te. Mas vejo que foi tu. Foi sempre tu que me chamavas". 
um dos momentos de uma cadeia de eventos que inicia com a morte de um menino por afogamento. Trata-se de eventos que aproximam o garoto Jack do que as freiras chamaram de natureza; diz ele, em "off”, após o afogamento: "Where were you? You let a boy die. You let anything happen". E logo depois: "Why should I be good? When you aren't". ${ }^{25}$

Nessa errância de Jack, mostrada como um afastamento da graça rumo à natureza, ou seja, do afogamento do menino à cena com a arma de pressão, o principal momento de calma ocorre quando o Sr. O'Brien se ausenta em viagem. Mesmo nesse período, porém, Jack choca-se com a mãe, por exemplo, no episódio do sapo que os garotos amarram em um foguete que, ao voar, causa a morte do animal. Ele só experimenta algo diferente quando entrega um pedaço de madeira a R. L., sugerindo que revide a lesão causada pela arma de pressão; o irmão, ao invés de usá-lo, perdoa Jack.

Na sequência, logo depois da frase que dirige a Deus ("I didn't know how to name you..."), ocorrem dois instantes daquilo que Aristóteles chama de philía: primeiro Jack auxilia um amigo a consertar um brinquedo composto por uma lata e uma corda; depois, de forma espontânea, auxilia o pai na horta. Diz Aristóteles do amor: "Seja amar o querer para alguém o que se julga bom, para ele e não para nós, e também o ser capaz de realizá-lo na medida do possível" (Ret. 1380b35-1381a 1). A sequência de imagens mostra que, aqui, o Sr. O'Brien é, para o filho, alguém que não lhe causa temor e em quem confia, condições para o amor, segundo Aristóteles, e que se manifestam na forma como Jack coloca a mão no ombro do amigo e no silêncio que une pai e filho na horta. ${ }^{26}$ Não se trata da calma aristótelica, que sentimos quando junto daqueles que tememos ou respeitamos. ${ }^{27}$

25 “Onde estavas? Deixaste um garoto morrer. Deixas qualquer coisa ocorrer... Por que eu deveria ser bom? Quando tu não o és". Para Rybin (2012, p. 176), essa questão de Jack pode estar sendo posta para a mãe, o pai, Deus, o irmão morto ou a si mesmo quando jovem. Parece-me, porém, que essa interpretação - é bem verdade que seu texto sobre $A$ árvore da vida no livro sobre os filmes anteriores de Malick é um pós-escrito, pois o filme foi lançado quando o livro já estava virtualmente concluído - busca evitar, a todo custo, uma interpretação judeo-cristã do filme; não surpreende, portanto, que, no outro extremo, Leithart (2013) diminua a importância do que vai contra essa tradição, como, por exemplo, o discurso darwinista.

26 “(Sc. E, em geral, amamos) aqueles que não causam temor e aqueles em quem confiamos, pois ninguém ama a quem teme" (Ret. 1381b 32-33).

27 "Sentimos tranquilidade junto àqueles a quem tememos ou respeitamos" (Ret. 1380a 32). 
Nesse momento, inicia a música que acompanha uma longa narrativa em "off" do Sr. O'Brien, o qual revela a confusão que faz entre ser amado e ser admirado: "I wanted to be loved because I was great. A big man. I am nothing". ${ }^{28}$ Vemo-lo na fábrica em enquadramentos que lembram Jack adulto em seu trabalho. No momento em que diz que gostaria de ter sido grande, mas que é nada, aparece chegando do trabalho, a câmara postada dentro de sua casa, enquadrando parte da porta para a varanda. Quando diz "look, the glory around us", ${ }^{29}$ quem se vê é a mãe caminhando no centro da cidade e sorrindo, reforçando que aquilo que se vê faz parte de uma busca anímica de Jack adulto. A voz em "off" continua, com a imagem do Sr. O'Brien dentro de casa - "I dishonored it all and didn't notice the glory. A foolish man" ${ }^{30} \mathrm{e}$ então o ouvimos falar diretamente com a esposa que entrara na sala carregando um vaso com flores: "They're closing the plant. They gave me a choice. No job. Or transfer to a job nobody wants". ${ }^{31}$ De relance, vemos Jack espiar a conversa. A sequência, então, é uma intensa demonstração de amor de Jack pelo pai, intercalando-se imagens que mostram o amor entre o pai e filho, o pai e a mãe, e dois discursos que se entrelaçam, um, a voz em "off" do garoto Jack ("Father... Mother... Always you wrestle inside me. Always you will"); ${ }^{32}$ o outro, o do Sr. O'Brien, que faz a sua profissão de fé ("I never missed a day of work... Tithe every Sunday"). ${ }^{33}$ Ambos, nesse momento, estão calmos contra aquilo que lhes provocara cólera anteriormente: o mundo do trabalho, no caso do Sr. O'Brien; o êthos do próprio pai, no caso de Jack. Para Jack, essa calma é a aceitação da forma como o pai diz ter agido com ele: "You know Jack, all I ever wanted for you was... Make you strong, and grow up and be your own boss. Maybe I've been tough on you. I'm not proud of that". ${ }^{34}$ Isso é o mais próximo a que o pai chega de um arrependimento, e, de fato, diz Aristóteles que "somos calmos... com os que reconhecem seus erros e se arrependem" (Ret. 1380a 12 e 14-15).

\footnotetext{
28 "Eu queria ser amado porque eu era ótimo. Um grande homem. Não sou nada". 29 "Veja, a glória em nossa volta".

30 "Desonrei tudo e não percebi a glória. Um homem tolo".

31 "Estão fechando a fábrica. Deram-me uma escolha. Sem trabalho. Ou transferência para um trabalho que ninguém quer".

32 "Pai... Mãe... Vocês sempre lutam dentro de mim. Sempre lutarão".

33 "Nunca perdi um dia de trabalho... Dízimo todo domingo".

34 "Você sabe, Jack, tudo que sempre quis para você foi... Torná-lo forte, crescer e ser seu próprio chefe. Talvez tenha sido muito duro com você. Não tenho orgulho disso".
} 
Todavia, se em Aristóteles a tranquilidade está ligada ao temor e ao respeito, nessa cena, por sua vez, parece haver mistura entre esses sentimentos e o amor. A forma como pai e filho se tocam nessa passagem ao mesmo tempo lembra a garota e seu pai no início do filme e se opõe a outras demonstrações de carinho entre o pai e seus filhos. No caso da menina, trata-se de uma total comunhão; no caso de Jack e do pai, parece haver uma consciência do corpo e das próprias emoções que torna a proximidade algo estranha. Nesse sentido, textos românticos basilares, como os ensaios "Poesia ingênua e sentimental", de Schiller, e especialmente "Sobre o teatro de marionetes", de Kleist (em uma curta cena, a Sra. O’Brien dança levitando sobre a terra!), me parecem intertextos importantes do filme, mas renderia outro texto o profícuo diálogo que este e outros filmes de Malick estabelecem com essa tradição.

Agradeço à Maria Cecília de Miranda N. Coelho pelo convite para participar do "I Seminário Docere, delectare et movere: emoções aristotélicas no cinema" (Centro de Convenções do Complexo Santuário do Caraça, de 10 a 13 de março de 2015) e por ter proporcionado o cenário, a atmosfera e o público ideais para as discussões.

\section{Referências}

ARISTÓTELES. Retórica das paixões. Trad: I. B. Fonseca. São Paulo: Martins Fontes, 2000.

KONSTAN, D. Aristotle on anger and the emotions: the strategies of status. In: BRAUND, S.; MOST, G. W. Ancient anger: perspectives from Homer to Galen. Cambridge: Cambridge University Press, 2003, p. 99-120.

KONSTAN, D. The emotions of the ancient Greeks: studies in Aristotle and classical literature. Toronto: University of Toronto Press, 2006.

LEITHARDT, P. J. Shining glory: theological reflections on Terrence Malick's Tree of life. Eugene: Cascade, 2013.

RYBIN, S. Terrence Malick and the thought of film. Lanham: Lexington, 2012.

TUCKER, T. D.; KENDALL, T. Introduction. In: Malick: film and philosophy. New York: Continuum, 2011. 